\title{
A New Method for Determining Linear Thermal Expansion of Invar Geodetic Surveying Tapes
}

\author{
Peter Hidnert and Richard K. Kirby
}

\begin{abstract}
In the new method an invar tape is heated by passing direct current through it while the ambient temperature is held constant. Observations of changes in length and electrical resistance are taken at different constant temperatures of the tape. The temperature coefficient of resistance of each tape is obtained experimentally or from a relationship, derived by the authors, between temperature coefficients of resistance and mass resistivities. The actual temperatures of the tape are determined from its different resistances and temperature coefficient of resistance. Coefficients of expansion determined by this method from $15^{\circ}$ to $35^{\circ} \mathrm{C}$ are in good agreement with those obtained by the method used previously at the Bureau. With the new method greater precision is obtained in a much shorter time than with the old method, and the observers are not subjected to widely different ambient temperatures.
\end{abstract}

\section{Introduction}

Determinations of the linear thermal expansion of 50 -meter geodetic tapes have been made at the $\mathrm{Na}$ tional Bureau of Standards for a half century. A view of the new Tape Testing Laboratory $[1,2],{ }^{1}$ which has been in use since 1950, is shown in figure 1 . Up to the present time, measurements of the lengths of the tapes have been made at several different constant temperatures ranging from about $5^{\circ}$ to $35^{\circ}$ C. These constant temperatures of the tapes were obtained by changing the ambient temperature of the entire laboratory. From these measurements of length and temperature, coefficients of linear thermal expanion were derived.

The work described in this paper was undertaken to develop a new method for determining coefficients of linear thermal expansion of invar ${ }^{2}$ geodetic tapes that would not involve changing the ambient temperature of the laboratory. To accomplish this, the plan was to heat the tapes to various temperatures by passing electric current through them.

After a preliminary investigation of some relationships between the thermal and electrical characteristics of short pieces of invar tapes, it was decided to derive the coefficients of expansion of $50-\mathrm{m}$ invar tapes from two separate series of measurements. One series was of the electrical resistance of the tapes versus ambient temperature (ranging from $0^{\circ}$ to $50^{\circ} \mathrm{C}$ ) and the other of the linear expansion versus electrical resistance ${ }^{3}$ (when direct current is passed through the invar tapes).

\footnotetext{
1 Figures in brackets indicate the literature references at the end of this paper. ${ }^{2}$ Invar, a nickel steel containing about 36 percent of nickel, has a small coefficient of linear thermal expansion ranging from about $-0.5 \times 10^{-6}$ to $+2.0 \times 10^{-6}$ per deg $\mathrm{C}$ at atmospheric temperatures. For this reason, invar has many applications; for example, it is used in the manufacture of geodetic tapes and wires, length standards, thermostats, and pendulum rods for clocks. However, invar has two disadvantages for very precise work. Its coefficient of expansion and its dimendisadvantages for very precise work. Its coeffcient of expansion and its dimenand cooling to its initial temperature, even though the change in temperature is small.

${ }_{3}$ The National Physical Laboratory [3] developed a method for determining ${ }^{3}$ The National Physical Laboratory [3] developed a method for determining
the lengths of steel tapes in terms of their electrical resistances without any knowlthe lengths of steel tapes in terms of their electrical resistances without any knowl-
edge of their temperatures. Their method, developed for laboratory and field edge of their temperatures. Their method, developed for laboratory and fieff. cients of thermal expansion.
}

\section{Tapes Investigated}

The 13 invar tapes and two steel tapes listed in table 1 were investigated. The invar tapes were 6.3 to $6.4 \mathrm{~mm}$ wide and 0.4 to $0.6 \mathrm{~mm}$ thick. The steel tapes were $6.3 \mathrm{~mm}$ wide and $0.3 \mathrm{~mm}$ thick.

TABLE 1. Description of 50-m tapes investigated

\begin{tabular}{|c|c|}
\hline $\begin{array}{c}\text { Tape } \\
\text { number }\end{array}$ & Source and identification \\
\hline \multicolumn{2}{|r|}{ Invar } \\
\hline $\begin{array}{l}1^{\mathrm{a}} \\
2 \\
3 \\
4^{\mathrm{a}} \\
5\end{array}$ & $\begin{array}{l}\text { Driver-Harris Co., H } 18 . \\
\text { Keuffel \& Esser Co., K\&E } 3482 \text {. } \\
\text { Keuffel \& Esser Co., K\&E } 3483 . \\
\text { Société Genevoise, Geneva, Swit- } \\
\text { zerland, BS 4939. } \\
\text { Société Genevoise, Geneva, Swit- } \\
\text { zerland, NBS 5276. }\end{array}$ \\
\hline $\begin{array}{r}6 \\
7 \\
8 \\
9 \\
10\end{array}$ & $\begin{array}{l}\text { Sociêté Genevoise, Geneva, Swit- } \\
\text { zerland, NBS 5277. } \\
\text { Société Genevoise, Geneva, Swit- } \\
\text { zerland, NBS 5278. } \\
\text { Keuffel \& Esser Co., K\&E } 6288 \text {. } \\
\text { Keuffel \& Esser Co., K\&E } 6293 . \\
\text { Keuffel \& Esser Co., K\&E } 6816 \text {. }\end{array}$ \\
\hline $\begin{array}{l}11 \\
12 \\
13\end{array}$ & $\begin{array}{l}\text { Keuffel \& Esser Co., K\&E } 6821 . \\
\text { Keuffel \& Esser Co., K\&E } 6839 \text {. } \\
\text { Keuffel \& Esser Co., K\&E } 7211 .\end{array}$ \\
\hline \multicolumn{2}{|r|}{ Steel } \\
\hline $\begin{array}{l}14 \\
15\end{array}$ & $\begin{array}{l}\text { Keuffel \& Esser Co., K\&E } 7829 . \\
\text { Lufkin Rule Co., NBS } 7830 .\end{array}$ \\
\hline
\end{tabular}

a Tape 1 was a piece $2.76 \mathrm{~m}$ long and tape 4 a piece $1.61 \mathrm{~m}$ long from the invar ribbons from which the $50-\mathrm{m}$ tapes were made.

\section{Apparatus and Method}

The procedures used in obtaining measurements of electrical resistance versus ambient temperature and of linear expansion versus electrical resistance are given in this section. Each 50-m tape was wound in a flat spiral having an outside diameter of about $25 \mathrm{~cm}$. The turns were electrically insulated from one another with adhesive cellophane tape. The coiled tape was placed horizontally by itself in a heating and cooling cabinet with a copper wire (AWG No. 12) of negligible resistance attached near 


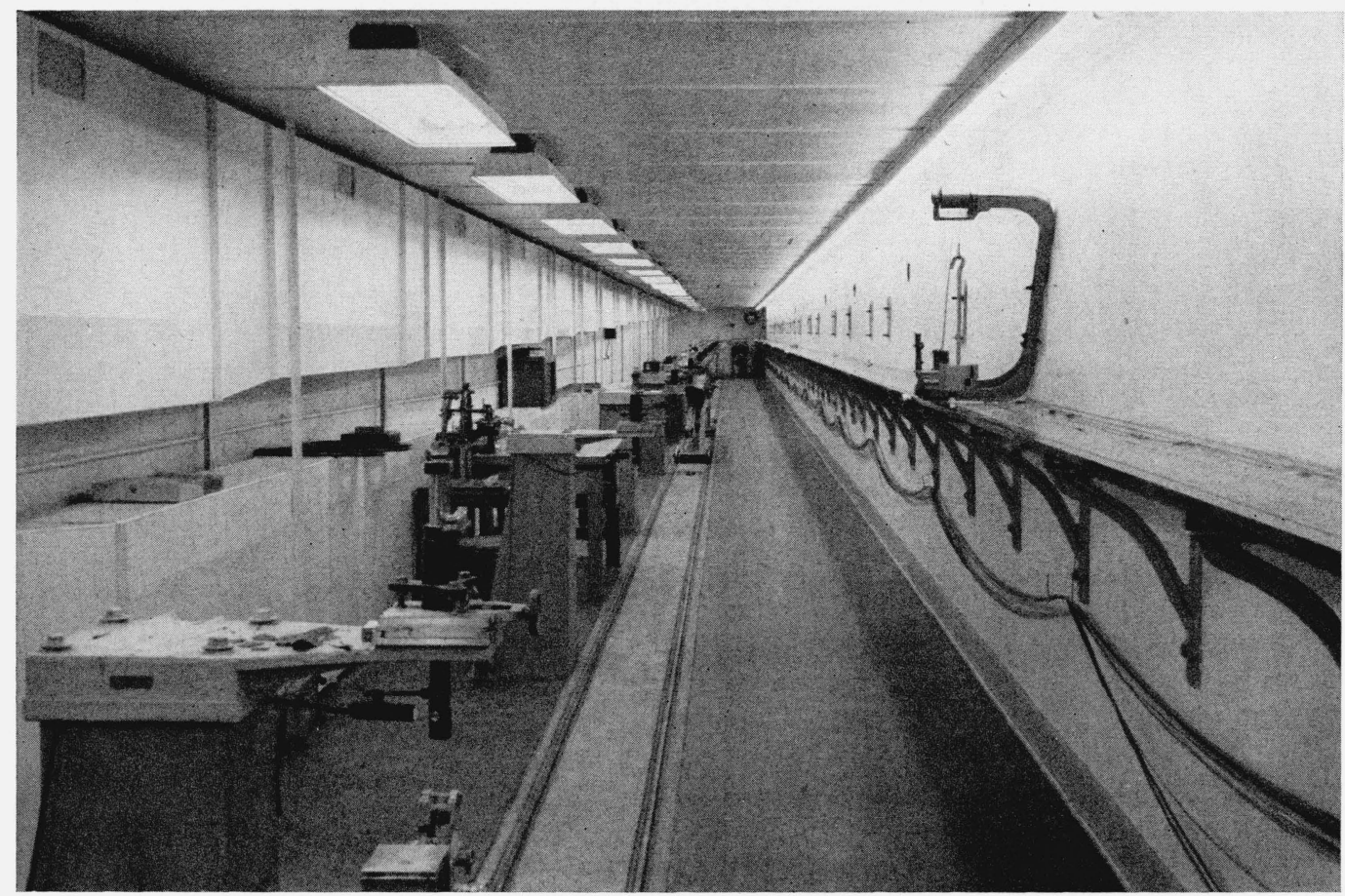

Figure 1. New NBS Tape Testing Laboratory.

each end of the tape. These wires extended out of the cabinet and were connected to a portable Wheatstone bridge for determinations of electrical resistance of the tapes. Four copper-constantan thermocouples placed at different positions near the coiled tape were used for determinations of temperature. The cabinet was heated and cooled to different temperatures between $0^{\circ}$ and $50^{\circ} \mathrm{C}$, and determinations of electrical resistance of the tape were made at various constant ambient temperatures in this temperature range, with no tension applied to the tape.

The 50-m tape was then unwound, cleaned of cellophane tape, and mounted in the 50-m geodetic comparator in the NBS Tape Testing Laboratory. The tape was supported at the $0-, 25-$, and $50-\mathrm{m}$ points and was electrically insulated from the supports and tension apparatus. The specified tension of $15 \mathrm{~kg}$ was applied to each invar tape and specified tensions of 25 and $20 \mathrm{lb}$ to steel tapes 14 and 15 , respectively. The temperature of the laboratory was maintained by thermostatic control at about $15^{\circ} \mathrm{C}$, and the actual temperature was determined several times during each test by means of 11 thermometers hung near the tape at 5-m intervals. No thermometers were attached to the tape. The tape was heated to various temperatures by passing direct current ${ }^{4}$ through it. The linear expansion was determined from observations with two micrometer microscopes focused on the terminal graduations defining the nominal $50-\mathrm{m}$ interval of the tape. The electrical resistance corresponding to each observation of linear expansion was determined by the potentiometer method indicated in figure 2. As these obser-

\footnotetext{
For the tapes investigated, it was found that a current of about $4.2 \mathrm{amp}$ for
the invar and about $6.0 \mathrm{amp}$ for the steel tapes was required to maintain the the invar and about $6.0 \mathrm{amp}$ for the steel tapes was required
temperature 20 deg $\mathrm{C}$ above the ambient temperature $\left(15^{\circ} \mathrm{C}\right)$.
}

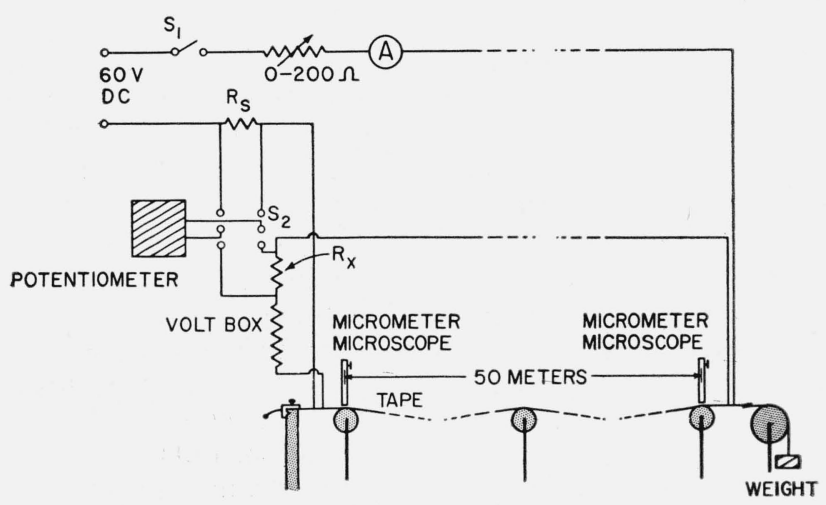

Figure 2. Schematic diagram of potentiometer method for determing electrical resistance of geodetic tapes.

vations of expansion versus resistance of the tape can be completed in a few hours, ${ }^{5}$ measurements of the lengths of the tape by means of the geodetic comparator as required in the old method are no longer needed for expansion determinations. The electrical resistance was computed from the equation

$$
R_{T}=\frac{k R_{S} E_{T}}{E_{S}-\frac{R_{S}}{R_{X}} E_{T}},
$$

where $R_{T}$ is the resistance of the tape (in ohms) between the potential connections, $k$ is the multiplying factor of the volt box (500.075), $R_{X}$ is the resistance of the section of the volt box connected across the potentiometer $(6.00 \mathrm{ohms}), E_{T}$ is the voltage drop across $R_{X}$ so that $k E_{T}$ is the voltage drop across the tape, $R_{S}$ is the resistance of the four-terminal current shunt $(0.010007 \mathrm{ohm})$, and $E_{S}$ is the voltage

${ }^{5}$ Experience has shown that the distance between the piers on which the microscopes are mounted remains quite constant over short periods of time. 
drop across $R_{S}$. Substituting the values for $k, R_{S}$, and $R_{X}$, eq (1) becomes

$$
R_{T}=\frac{5.0043 E_{T}}{E_{S}-0.00167 E_{T}} .
$$

Before each observation of linear expansion and the corresponding electrical resistance, the current was maintained constant until the readings obtained with the microscopes indicated a steady state. In the case of the steel tapes, satisfactory steady state conditions were not attained for reasons indicated later.

During the latter part of the investigation, a different volt box and a different four-terminal current shunt were used in the potentiometer method. The new current shunt had a resistance, $R_{S}$, of $0.10000 \mathrm{ohm}$. The multiplying factor, $k$, of the new volt box was 50.005, and the resistance of its section across the potentiometer, $R_{X}$, was 150 ohms. These values of the two instruments were chosen so that the potentiometer could measure larger voltage drops, thereby increasing the accuracy of resistance determinations. When the new values for $k, R_{S}$, and $R_{X}$ are substituted in eq (1) it becomes

$$
R_{T}=\frac{5.0005 E_{T}}{E_{S}-0.000667 E_{T}} .
$$

\section{Results and Discussion}

Data obtained by the new method on 2 invar tapes and 1 steel tape are shown in figures 3 to 5 , inclusive.

The bottom graph of each figure shows the observations obtained on the electrical resistance of the tape at various ambient temperatures from about $5^{\circ}$ to $50^{\circ} \mathrm{C}$. For each of the 13 invar tapes investigated, the relation between the electrical resistance ${ }^{6}$ and temperature may be represented by a curve concave toward the temperature axis. Honkasalo [4] found a similar relation between the electrical resistance and temperature of an invar wire between $15^{\circ}$ and $60^{\circ} \mathrm{C}$. The relation between the electrical resistance and temperature for the two steel tapes is essentially linear. Average temperature coefficients of resistance of the 15 tapes for several temperature ranges are given in table 2 . The temperature coefficients of electrical resistance of the invar tapes decrease with increasing temperature, but the temperature coefficients of the steel tapes are constant. The coefficients of resistance of the steel tapes are about twice as large as those for the invar tapes.

The central graphs of figures 3 to 5 , inclusive, show the observations obtained on the linear expansion corresponding to changes in electrical resistance of the same three tapes when they were heated by

- Experiments with two invar tapes indicated that an increase in tension from 0 to $15 \mathrm{~kg}$ caused the resistance to increase by a small, but negligible, amount.
TABLE 2. Temperature coefficients of electrical resistance of

\begin{tabular}{|c|c|c|c|}
\hline \multirow{2}{*}{$\begin{array}{l}\text { Tape } \\
\text { Number }\end{array}$} & \multicolumn{3}{|c|}{$\begin{array}{l}\text { A verage temperature coefficients of electrical } \\
\text { resistance per deg C }\end{array}$} \\
\hline & $15^{\circ}$ to $25^{\circ} \mathrm{C}$ & $15^{\circ}$ to $35^{\circ} \mathrm{C}$ & $15^{\circ}$ to $45^{\circ} \mathrm{C}$ \\
\hline \multicolumn{4}{|c|}{ Invar } \\
\hline $\begin{array}{l}1 \\
2 \\
3 \\
4 \\
5\end{array}$ & $\begin{array}{r}0.00166 \\
.00156 \\
.00144 \\
.00146 \\
.00179\end{array}$ & $\begin{array}{l}0.00163 \\
.00152 \\
.00141 \\
.00142 \\
.00178\end{array}$ & $\begin{array}{r}0.00161 \\
.00150 \\
.00137 \\
.00140 \\
\end{array}$ \\
\hline $\begin{array}{r}6 \\
7 \\
8 \\
9 \\
10\end{array}$ & $\begin{array}{l}.00184 \\
.00176 \\
.00142 \\
.00144 \\
.00149\end{array}$ & $\begin{array}{l}.00177 \\
.00167 \\
.00140 \\
.00139 \\
.00142\end{array}$ & $\begin{array}{c}.00172 \\
.00163 \\
\end{array}$ \\
\hline $\begin{array}{l}11 \\
12 \\
13\end{array}$ & $\begin{array}{l}.00146 \\
.00141 \\
.00159\end{array}$ & $\begin{array}{l}.00142 \\
.00138 \\
.00149\end{array}$ & 00136 \\
\hline \multicolumn{4}{|c|}{ Steel } \\
\hline $\begin{array}{l}14 \\
15\end{array}$ & $\begin{array}{r}0.00315 \\
.00306\end{array}$ & $\begin{array}{r}0.00315 \\
.00306\end{array}$ & $\begin{array}{r}0.00315 \\
.00306\end{array}$ \\
\hline
\end{tabular}
invar a and steel surveying tapes

a Hunter [5] stated that the temperature coefficient of electrical resistivity of invar is of the order of 0.0012 per deg C "over the range of low expansivity." The following temperature coefficients of electrical resistance for an invar wire were computed from data obtained by Honkasalo [4]: $0.00194,0.00189$, and 0.00184 for the ranges from $15^{\circ}$ to $25^{\circ}, 15^{\circ}$ to $35^{\circ}$, and $15^{\circ}$ to $45^{\circ} \mathrm{C}$, respectively.

passing direct current through them. The straight lines and the curve indicate the relations between linear expansion and change in electrical resistance of the tapes.

When passing a current of 1 amp or more through steel tapes 14 and 15 , it was impossible to determine their linear expansion with the same absolute precision as for the invar tapes. Large fluctuations in length were observed at the microscope focused on the 50-m graduation of each of these tapes, when the other end of each tape was clamped in a fixed position. These variations in length of the steel tapes were caused by momentary temperature changes produced chiefly by air-convection currents around the tapes. Slight or no fluctuations in length of the invar tapes were observed because their coefficients of expansion are very small, about one-thirtieth that of the steel tapes.

The straight lines and the curve in the top graphs of figures 3 to 5 , inclusive, represent the relations between linear expansion and temperature, which were derived from the relations indicated in the lower graphs of these figures. Table 3 gives average coefficients of linear thermal expansion obtained from the top graphs of the figures. This table also includes coefficients of expansion for these tapes on other tests and for four other tapes from similar data.

After the determinations of the coefficients of expansion of 5 invar and 2 steel tapes had been completed by the new method, determinations of the coefficients of expansion of these tapes were made by the former (old) method. In this former method, the temperature of each tape was determined from the readings of 11 thermometers. Two of these 
TABLE 3. Coefficients of linear thermal expansion of five invar and two steel surveying tapes by new method

\begin{tabular}{|c|c|c|c|}
\hline $\begin{array}{l}\text { Tepe } \\
\text { number }\end{array}$ & $\begin{array}{c}\text { Test } \\
\text { number } \mathrm{s}\end{array}$ & $\begin{array}{l}\text { Tempera- } \\
\text { ture range }\end{array}$ & $\begin{array}{c}\text { A verage } \\
\text { coefficient } \\
\text { of expan- } \\
\text { sion rer } \\
\text { deg C }\end{array}$ \\
\hline \multicolumn{4}{|c|}{ Invar } \\
\hline $\begin{array}{l}3 \ldots \\
6 \ldots \\
7 \ldots \ldots \\
12 \ldots\end{array}$ & $\begin{array}{l} \begin{cases}1 \\
2 \\
1\end{cases} \\
\begin{array}{l}\text { b } 2 \\
3 \\
\text { b } 4 \\
1 \\
1 \mathrm{H} \\
1 \mathrm{C} \\
1 \\
\text { b } 2\end{array}\end{array}$ & $\begin{array}{c}\quad{ }^{\circ} C \\
15 \text { to } 35 \\
15 \text { to } 35 \\
15 \text { to } 35 \\
15 \text { to } 35 \\
15 \text { to } 35 \\
15 \text { to } 35 \\
15 \text { to } 35 \\
15 \text { to } 35 \\
15 \text { to } 35 \\
15 \text { to } 35 \\
15 \text { to } 35\end{array}$ & $\begin{array}{l}0.36 \times 10^{-6} \\
.39 \\
.62 \\
.60 \\
.57 \\
.58 \\
.16 \\
.16 \\
.12 \\
.35 \\
.39\end{array}$ \\
\hline \multicolumn{4}{|c|}{ Steel } \\
\hline $\begin{array}{l}14 \ldots \\
15\end{array}$ & $\begin{array}{l}1 \mathrm{H} \\
1 \mathrm{C} \\
1 \mathrm{H} \\
1 \mathrm{C} \\
2 \\
3\end{array}$ & $\begin{array}{l}15 \text { to } 28 \\
15 \text { to } 28 \\
15 \text { to } 35 \\
15 \text { to } 35 \\
15 \text { to } 30 \\
15 \text { to } 23\end{array}$ & $\begin{array}{r}10.2 \\
9.8 \\
11.7 \\
12.1 \\
12.8 \\
10.7\end{array}$ \\
\hline
\end{tabular}

- $\mathrm{H}$ indicates that the coefficient of expansion was obtained on heating and $\mathrm{C}$, on cooling. In cases where $\mathrm{H}$ or $\mathrm{C}$ are not indicated, coefficients of expansion were obtained from data on both heating and cooling.

b A different volt box and a different four-terminal current shunt were used for this test.

thermomenters, each weighing $45 \mathrm{~g}$, were attached to the tape $1 \mathrm{~m}$ inside the terminal graduations. The remaining nine thermometers were suspended in close proximity to the tape at $5-\mathrm{m}$ intervals from 5 to 45 $\mathrm{m}$ along the length of the tape. The following horizontal tensions were used in both methods: $15 \mathrm{~kg}$ for the invar tapes, $25 \mathrm{lb}$ for steel tape 14 , and $20 \mathrm{lb}$ for steel tape 15 .

The coefficients of expansion of the tapes by the former (old) method were obtained from the determinations of the lengths of the tapes at ambient temperatures of $20^{\circ}, 15^{\circ}, 35^{\circ}$, and $25^{\circ} \mathrm{C}$. These lengths were measured by comparison with a distance of $50 \mathrm{~m}$ determined by means of a $5-\mathrm{m}$ steel standard on each day that measurements were made. This 5 -m bar was packed in melting ice to maintain it at $0^{\circ} \mathrm{C}$. The apparatus and the tapes were kept in the Tape Testing Laboratory with the ambient temperature maintained within $\pm 0.5 \mathrm{deg}$ C. Observed values for the length of a 50-m tape at each temperature seldom vary more than about \pm 25 microns $^{7}$ from the mean, the greatest differences in length usually occurring between values obtained on different days. After the ambient temperature of the laboratory was changed to another constant temperature, several days were allowed for the equipment to reach equilibrium conditions. The time between the first observations at $20^{\circ} \mathrm{C}$ and the final observations at $25^{\circ} \mathrm{C}$ for these seven tapes was 24 days.

Figures 6 to 8 , inclusive, show the observed linear

${ }^{7}$ Contributing causes that could account for these variations in length are changes in temperature, uneven distribution of temperature, small variable frictional effects in the tension pulleys and the support pulleys, errors in the defrictional effects in the tension pulleys and the support pulleys, errors in the dethe tape.
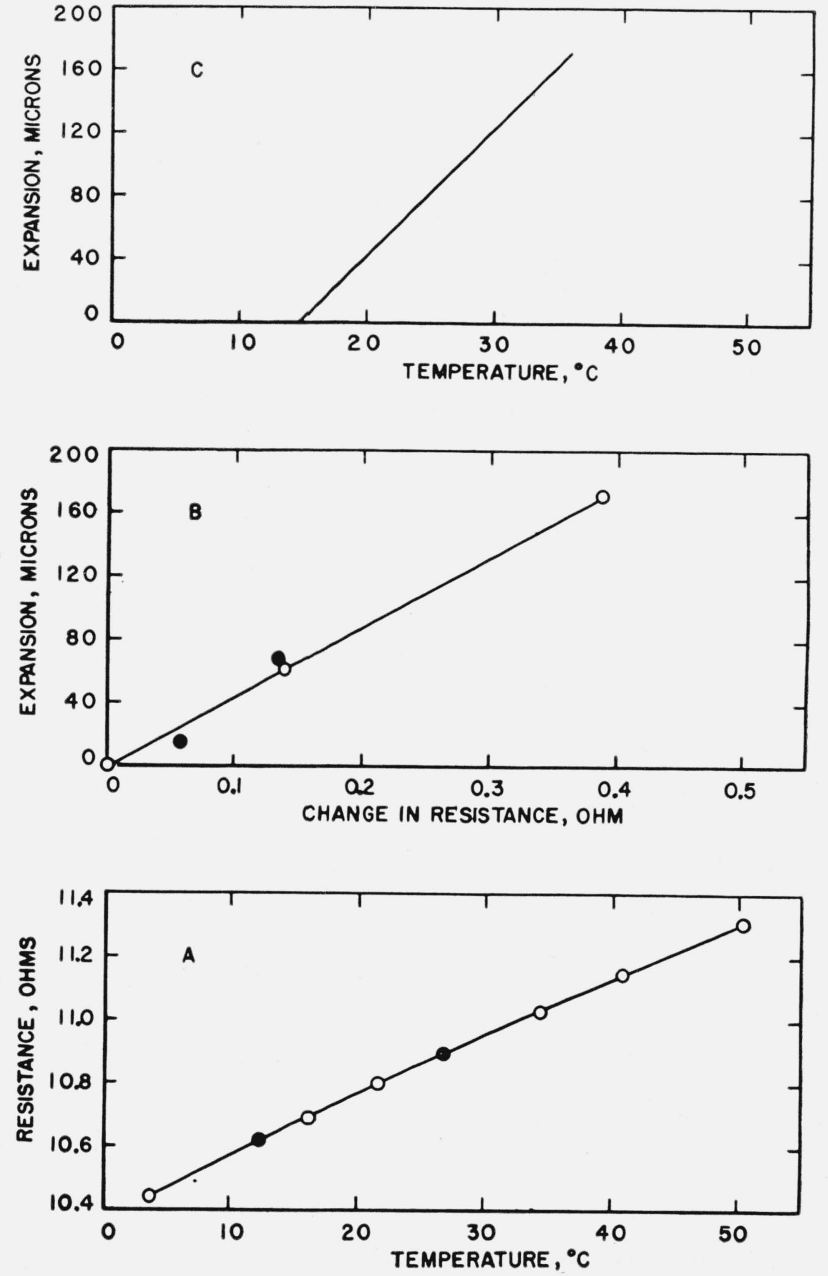

FIgURE 3. Observed and derived data on invar geodetic tape 6 by new method (second test).

$\bigcirc$, heating; $\mathbf{O}$, cooling.

A, Observed electrical resistance (ohms per 51.8 meters) versus temperature $\mathrm{B}$, Observed linear expansion (microns per 50 meters) versus change in electrical resistance (ohm per 50.4 meters) from resistance at $15^{\circ} \mathrm{C}$. The tape was heated by passing direct electric current through it. C, Derived relation between linear expansion (microns per 50 meters) and temperature, obtained from the observed data in $\mathrm{A}$ and $\mathrm{B}$.

thermal expansion of 2 invar tapes and 1 steel tape by the former method. These tapes are the same as those indicated in figures 3 to 5 , inclusive, showing data obtained by the new method. Straight lines representing relations between linear expansion and temperature for invar tape 6 and steel tape 14 were obtained by both methods. Curves representing relations between linear expansion and temperature for invar tape 12 were obtained by both methods.

Table 4 gives a comparison of the coefficients of linear thermal expansion of 5 invar tapes and 2 steel tapes by the new method with those obtained by the former method. The values of the coefficients of expansion of the invar tapes are in good agreement by the two methods. The average difference between the coefficients of expansion of the 5 invar tapes by the 2 methods is $0.03 \times 10^{-6}$. 

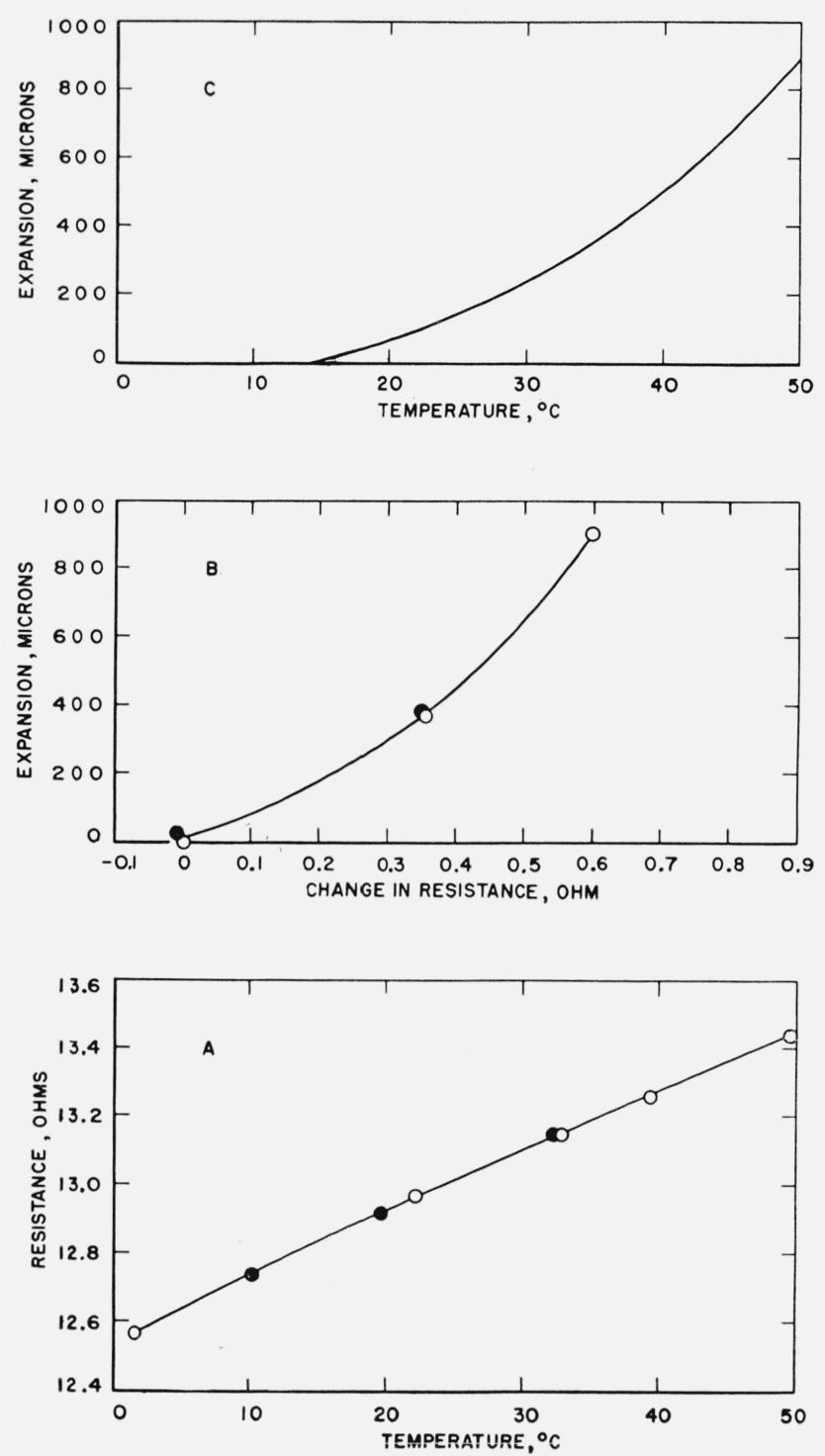

Figure 4. Observed and derived data inon invar. geodetic tape 12 by new method (second test). $\bigcirc$, heating; $\bullet$, cooling.

A,Observed electrical resistance (ohms per 51.2 meters) versus temperature B, Observed linear expansion (microns per 50 meters) versus change in electrica resistance (ohm per 50.4 meters) from resistance at $15^{\circ} \mathrm{C}$. The tape was heated by passing direct electric current through it. C, Derived relation between linear expansion (microns per 50 meters) and temperature, obtained from the observed data in $\mathrm{A}$ and $\mathrm{B}$.

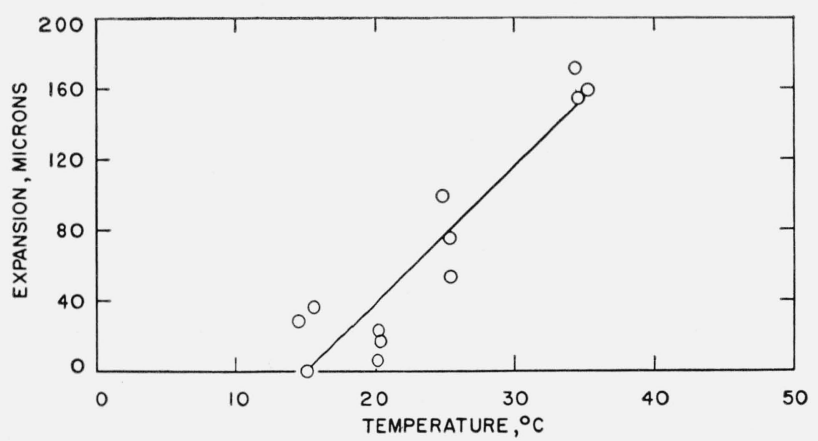

FIGURE 6. Observed linear thermal expansion of invar goedetic tape 6 by former method.
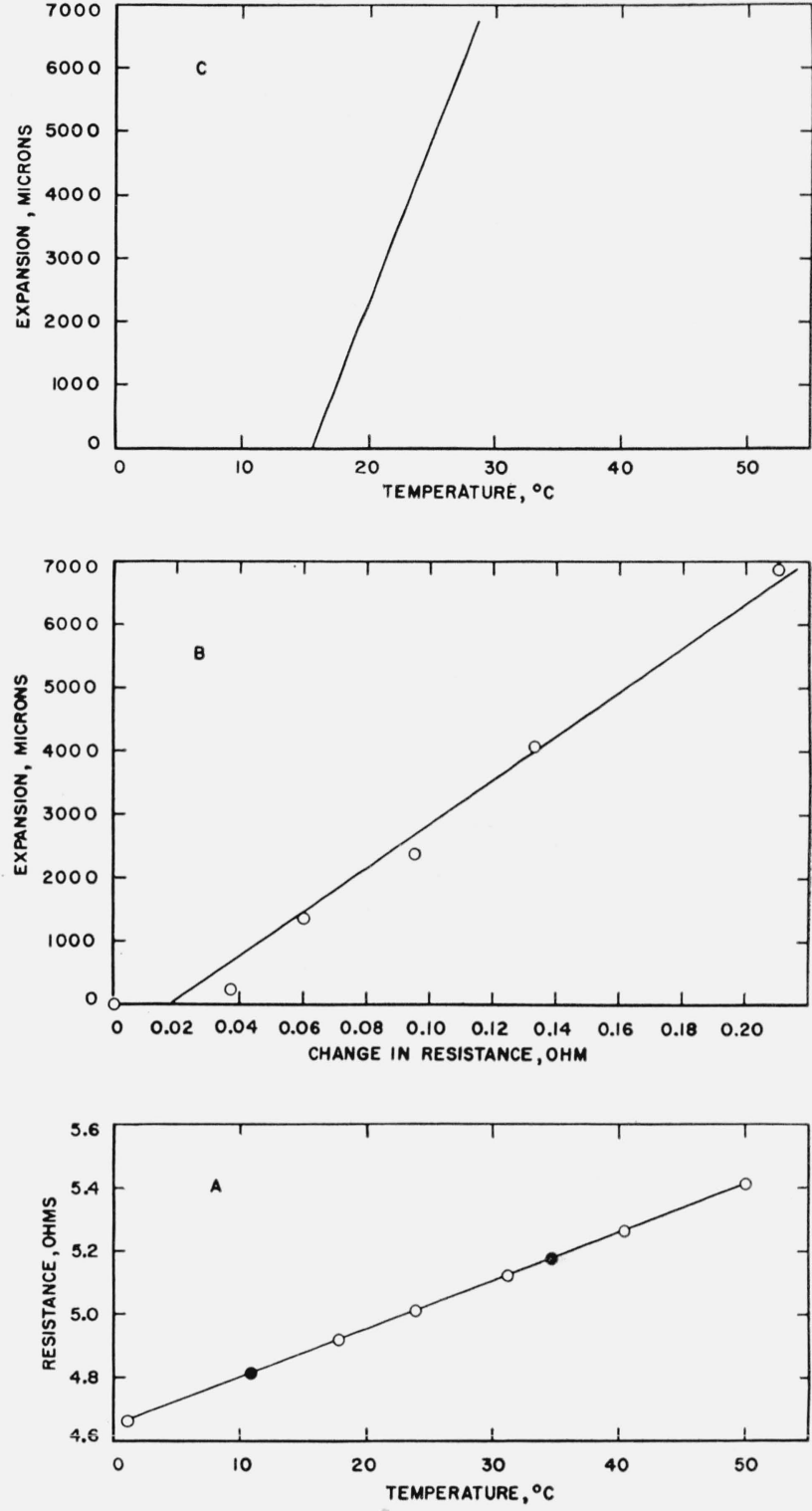

FIGURE 5. Observed and derived data on steel surveying tape 14 by new method.

$$
\bigcirc \text {, heating; • cooling. }
$$

A, Observed electrical resistance (ohms per 52.2 meters) versus temperature $\mathrm{B}$, Observed linear expansion (microns per 50 meters) versus change in electrical resistance (ohm per 50.4 meters) from resistance at $15^{\circ} \mathrm{C}$. The tape was heated resistance (ohm per 50.4 meters) from resistance at 15 . The tape was heated linear expansion (microns per 50 meters) and temperature, obtained from the observed data in $\mathrm{A}$ and $\mathrm{B}$.

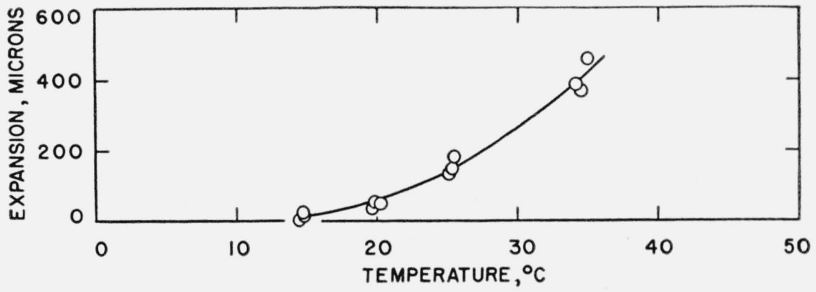

Figure 7. Observed linear thermal expansion of invar geodetic tape 12 by former method. 


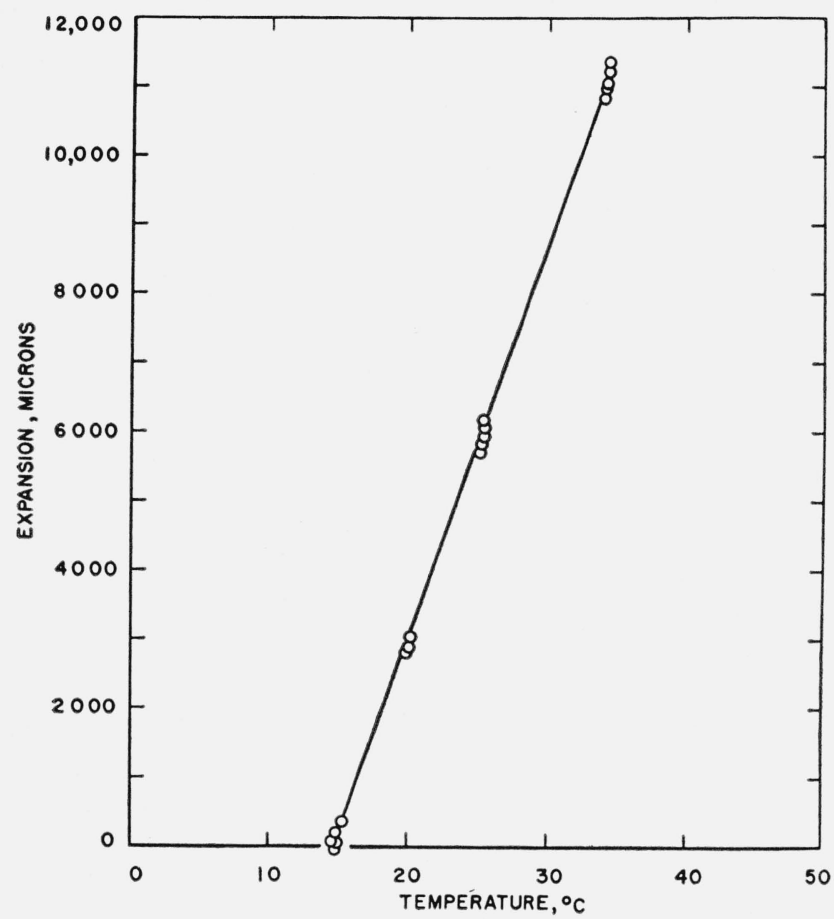

Figure 8. Observed linear thermal expansion of steel surveying tape 14 by former method.

TABLE 4. Comparison of coefficients of linear thermal expansion of invar and steel surveying tapes by new and former methods

\begin{tabular}{|c|c|c|c|}
\hline \multirow{2}{*}{$\begin{array}{c}\text { Tape } \\
\text { number }\end{array}$} & \multirow{2}{*}{ Material } & \multicolumn{2}{|c|}{$\begin{array}{l}\text { A verage coefficients of expan- } \\
\text { sion per degree } \mathrm{C} \text { from } 15^{\circ} \\
\text { to } 35^{\circ} \mathrm{C}\end{array}$} \\
\hline & & New methoda & Former method \\
\hline $\begin{array}{r}2 \\
3 \\
6 \\
7 \\
12 \\
14 \\
15\end{array}$ & $\begin{array}{l}\text { Invar } \\
\text { do do_el } \\
\text { Stedo } \\
\end{array}$ & $\begin{array}{c}0.38 \times 10^{-6} \\
.59 \\
.16 \\
.14 \\
.37 \\
\text { b } 10.0 \\
\text { c } 11.8\end{array}$ & $\begin{array}{l}0.41 \times 10^{-6} \\
.65 \\
.15 \\
.13 \\
.41 \\
11.4 \\
11.9\end{array}$ \\
\hline
\end{tabular}

a Values in this column are averages of the values in last column of table 3. b From $15^{\circ}$ to $28^{\circ} \mathrm{C}$.

- For three temperature ranges $\left(15^{\circ}\right.$ to $35^{\circ}, 15^{\circ}$ to $30^{\circ}$, and $15^{\circ}$ to $23^{\circ} \mathrm{C}$ ).

The probable error of the coefficients of expansion of the invar tapes by the new method is approximately $0.01 \times 10^{-6}$, which is about half as large as that of the coefficients of expansion determined by the former method. The lower probable error of the coefficients of expansion obtained by the new method may be credited to the fact that the linear expansion is measured directly in a short time, whereas in the former method, cumulative errors occurred in the measurement of the lengths of the tapes at each temperature.

Honkasalo [4] indicated that when an invar wire is subjected to rapid changes in temperature, the wire expands or contracts more than is presupposed by the coefficient of expansion, but the invar wire slowly regains the length set by the coefficient of expansion. He stated that if the effect due to

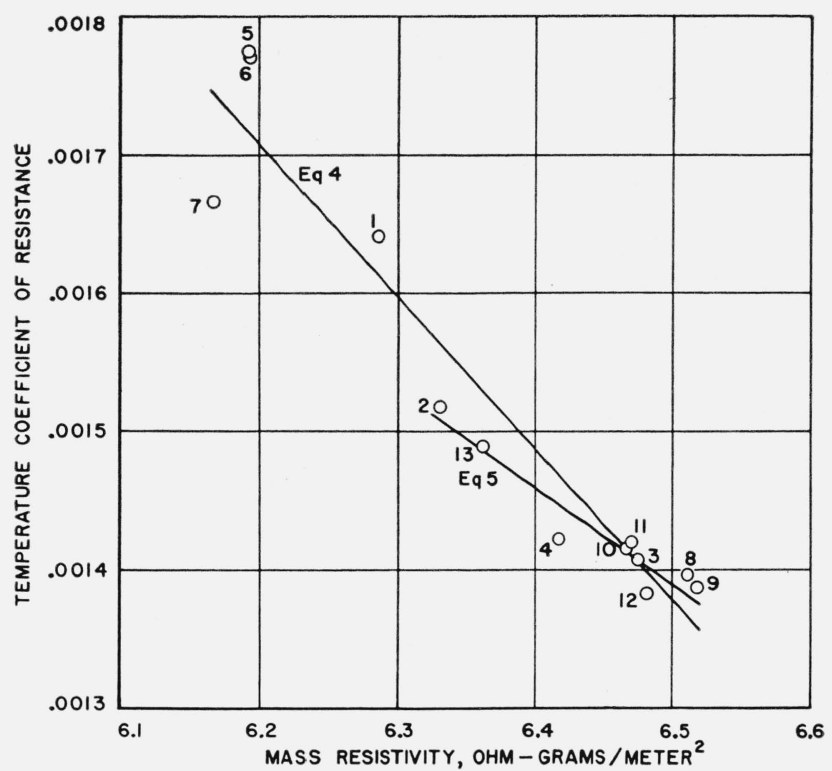

Figure 9. Relation between average temperature coefficient of electrical resistance $\left(15^{\circ}\right.$ to $\left.35^{\circ} \mathrm{C}\right)$ and mass resistivity at $15^{\circ} \mathrm{C}$ of invar tapes.

See equations 4 and 5.

hysteresis has not died down, the measurement will give a greater coefficient of expansion than that based on a change in temperature over a longer period of time. For stabilized ${ }^{8}$ invar tapes, the effect due to thermal hysteresis may be very small. Invar tapes used for precision measurements should from time to time be submitted to a standardizing laboratory for redeterminations of length.

In the course of this investigation, an empirical relationship was observed between the temperature coefficient of electrical resistance and mass resistivity ${ }^{9}$ of the invar tapes investigated. If it is assumed that this relationship holds for all invar tapes of the usual composition, it can be used to obtain temperature coefficients of resistance, and thus the time involved in the determinations of coefficients of thermal expansion will be reduced. The relationship shown in figure 9 indicates that the temperature coefficient of electrical resistance $\left(15^{\circ}\right.$ to $35^{\circ} \mathrm{C}$ ), $\alpha$, decreases linearly with increase in the mass resistivity (at $15^{\circ} \mathrm{C}$ ), $r_{m}$. The equation

$$
\alpha=0.00850-0.001096 r_{m}
$$

was derived by the method of least squares from the data on all of the invar tapes investigated. The probable error of $\alpha$ is \pm 0.00003 .

8 In order to reduce to a minimum the dimensional changes of invar wires on aging, Guillaume $[6,7]$ subjected them to a moderately elevated temperature for a prolonged time, for example $100^{\circ} \mathrm{C}$ for several days, and then allowed them to cool gradually to room temperature over an interval of about 3 months. Lement, Roberts, and Averbach [8] recently recommended the following treatment for invar in order to achieve satisfactory stress relief and high dimensional stability: (a) $830^{\circ} \mathrm{C}, 30$ minutes, water quench; (b) $315^{\circ} \mathrm{C}, 1$ hour, air cool; and (c) $95^{\circ} \mathrm{C}$, 48 hours, air cool.

9 Mass resistivity, product of resistance per unit length and mass per unit length expressed in this paper as ohm-grams/meter ${ }^{2}$, is a constant that is characteristic of the alloy (chemical composition and probably treatment). 
As most of the invar tapes investigated have mass resistivities between 6.3 and 6.6 ohm-grams $/$ meter $^{2}$, the equation

$$
\alpha=0.00585-0.000686 r_{m}
$$

derived from the data on these tapes may be used in preference to eq (4) for invar tapes within this range. ${ }^{10}$ The probable error of $\alpha$ from this equation is only \pm 0.00001 . For tapes having very small coefficients of thermal expansion, it is obviously not necessary to know the temperature coefficient of resistance as accurately as is required for tapes having large coefficients of thermal expansion.

On account of inhomogeneity (due to variations in chemical composition, heat treatment, mechanical treatment, etc.) along the length of an invar tape, the authors recommend that a determination of the coefficient of thermal expansion of the entire tape should be made. This recommendation is in agreement with Bonsdorff [9], who has shown that the coefficient of thermal expansion of a long invar tape or wire determined on its entire length cannot be assumed to be the same as that determined on a 1-m portion of the same tape or wire.

\section{Summary and Conclusions}

1. A new method for determining coefficients of linear thermal expansion of invar tapes has been developed.

2. Temperature coefficients of electrical resistance of invar tapes were determined first, and then determinations of linear expansion versus change in electrical resistance (when direct current was passed through the tapes) were made while the temperature of the laboratory itself was maintained at $15^{\circ} \mathrm{C}$. Micrometer microscopes were used in the observations of the linear expansion and a potentiometer method was used in determinations of the corresponding electrical resistance.

3. Coefficients of linear thermal expansion of invar tapes were derived from the temperature coefficients of electrical resistance and the relations between linear expansion and change in electrical resistance.

4. The coefficients of expansion of invar tapes by the new method are in good agreement with those obtained by the old method (table 4). For the procedure that has thus far been devised for the new method the probable error of the coefficients of expansion is about $0.01 \times 10^{-6}$.

10 Forty invar tanes were tested after this investigation was completed, and their mass resistivities were found to be within the range 6.36 to $6.51 \mathrm{ohm}$-grams/ meters ${ }^{2}$.
5. With the new method, the time required to make the determinations is considerably reduced and the observers are not subjected to widely different and uncomfortable ambient temperatures.

6. Data reported in the paper show that the temperature coefficient of electrical resistance of invar tapes decreases linearly with increase in the mass resistivity. The use of this relationship (eq 4 or 5) will further reduce the time required to make determinations.

7. It is recommended that one or more invar tapes with known coefficients of expansion, preferably $0.4 \times 10^{-6}$ per deg $\mathrm{C}$ or larger, be used in conjunction with invar tapes on which coefficients of expansion are to be determined by the new method, for checking the determinations.

The authors gratefully acknowledge their indebtedness to I. C. Gardner and L. V. Judson for their advice and encouragement during the development of the new method, to C. Peterson and F. K. Harris for their advice regarding determinations of electrical resistance, to R. F. Ackermann and J. S. Beers for assistance in the experimental work, and to H. F. Stimson for his helpful comments.

\section{References}

[1] L. V. Judson, Effect of concentrated loads on the length of measuring tapes, Sci. Pap. BS 21, 385 (1926) S534.

[2] L. V. Judson, Testing of measuring tapes at the Bureau of Standards, NBS Circ. 328 (1927)

[3] J. S. Clark and L. O. Johnson, Standardisation of steel surveying tapes, Engineer 191, 820 (1951).

[4] T. Honkasalo, Measuring of the 864 m-long Nummela standard base line with the Vaisala light interference comparator and some investigations into invar wires, Suomen Geodeettisen Laitoksen Julkaisuja, Veroffentlichungen des Finnischen Geodatischen Institutes, No. 37, Helsinki (1950).

[5] M. A. Hunter, Low-expansion alloys, Metals Handbook, Am. Soc. Metals, p. 601 (1948).

[6] C. E. Guillaume, Modifications de la dilatabilité de l'invar par des actions mécaniques ou thermiques, Compt. rend. 163, 654 (1916).

[7] C. E. Guillaume, Homogénéité de la dilatation de l'invar, Compt. rend. 163, 966 (1916).

[8] B. S. Lement, C. S. Roberts, and B. L. Averbach, Determination of small thermal expansion coefficients by a micrometric dilatometer method, Rev. Sci. Instr. 22, 194 (1951).

[9] I. Bonsdorff (Private communication from E. F. Gigas of Institut für Angewandte Geodäsie, Frankfurt a. M., Germany, April 15, 1952).

Washington, October 6, 1952. 